\title{
ANALISA UNJUK KERJA MESIN STEMPEL FLASH MADE IN TIONGKOK MEREK FLAZ TERHADAP MESIN STEMPEL FLASH MADE IN INDONESIA MEREK MD
}

\author{
${ }^{1}$ Slamet Raharjo, ${ }^{2}$ Massus Subekti, ${ }^{3}$ Imam Arif Rahardjo
}

1,2.3.Pendidikan Teknik Elektro, Universitas Negeri Jakarta

\begin{abstract}
This research aimed to find out the work method of flash stamp machine made in Tiongkok brand Flaz and flash stamp machine made in Indonesia brand MD observed from each machine performance including colour stamp quality resulted, duration in its operation, as well as power and electricity consumption.

The research method adopted is qualitative method with grounded theory approach. This research conducted in Enterprise of Flash Stamp Machine made in Indonesia brand MD on Jl. Lembang Baru I West Sudimara, Ciledug, Tangerang, Banten.

The result drawn from work method research of both flash stamp machine are: First, the stamp quality resulted by flash stamp machine brand MD was better than flash stamp machine brand MD. Second, the operation time of flash stamp machine brand MD was 4 second faster, that is 3 second, while flash stamp machine brand Flaz was 4 second. Third, the electricity power consumption of flash stamp machine brand Flaz was smaller that is 136,62 watt, while brand Flaz was 392,34 watt. Fourth, the electrical energy consumption of flash stamp machine Flaz was smaller that is 888,39 Joule, while flash stamp machine brand MD was 1709,06.

The conclusion drawn from work method research of flash stamp machine made in Tiongkok brand Flaz toward flash stamp machine made in Indonesia brand MD measured from stamp output quality parameter and operation time speed, so flash stamp machine made in Indonesia brand MD is better than flash stamp machine made in Tiongkok brand Flaz.
\end{abstract}

Keywords: Flash Stamp Machine, Work Method, Color Stamp

\begin{abstract}
Abstrak
Penelitian ini bertujuan untuk mengetahui unjuk kerja mesin stempel flash made in Tiongkok merek Flaz terhadap mesin stempel flash made in Indonesia merek MD dilihat dari performa masing-masing mesin meliputi kualitas cap stempel warna yang dihasilkannya, lama waktu pengoperasiannya, pemakaian daya serta konsumsi energi listriknya.

Metode penelitian yang di gunakan adalah metode kualitatif dengan pendekatan penelitian grounded theory. Penelitian ini dilakukan di Perusahaan Pembuatan Mesin Stempel Flash made In Indonesia merek MD di Jl. Lembang Baru I Kelurahan Sudimara Barat, Ciledug, Tangerang, Banten.

Hasil yang diperoleh dari penelitian unjuk kerja kedua mesin stempel flash ini adalah : Pertama, kualitas cap stempel yang dihasilkan mesin stempel flash merek MD lebih bagus dibandingkan mesin stempel flash merek Flaz. Kedua, lama waktu operasinya 4 detik lebih cepat mesin stempel flash merek MD yaitu selama 3 detik dan 4 detik untuk mesin stempel flash merek Flaz. Ketiga, daya listrik yang dibutuhkan lebih kecil mesin stempel flash merek Flaz yaitu sebesar 136,62 watt dan 392,34 Watt untuk merek Flaz. Keempat, konsumsi energi listrik yang dibutuhkan lebih kecil mesin stempel merek Flaz yaitu 888,39 Joule dan 1709,06 Joule untuk mesin stempel flash merek MD.

Kesimpulan yang diperoleh dari penelitian unjuk kerja mesin stempel flash made in Tiongkok merek Flaz terhadap mesin stempel flash made in Indonesia merek MD diukur dari parameter kualitas hasil cap dan kecepatan waktu operasi maka mesin stempel flash made in Indonesia merek MD lebih bagus dari pada mesin stempel flash made in Tiongkok merek Flaz.
\end{abstract}

Kata Kunci : Mesin Stempel Flash, Unjuk Kerja dan Stempel Warna

\section{PENDAHULUAN}

Mesin stempel flash adalah mesin elektronik yang fungsinya untuk membuat stempel warna, teknologi mesin stempel flash pertamakali dikenalkan oleh perusahaan Stamp Western \& Engraving Co. California, AS pada tahun 1998.

Di Indonesia mesin stempel flash ini tergolong alat yang langka dan mahal harganya. Seiring dengan berkembang zaman banyak orang yang mencoba membuat mesin stempel flash ini. Demikian juga dengan perkembangan teknologi yang terus maju beberapa desain rancangan mesin ini diciptakan sesuai kebutuhannya.

Berbagai mesin stempel flash yang sudah banyak beredar di masyarakat. Misalnya mesin stempel flash dengan lampu L buatan Tiongkok, mesin stempel flash dengan lampu tipe $\mathrm{R}$ buatan Tiongkok, mesin stempel flash dengan lampu tipe L 6080 buatan Indonesia dan mesin stempel flash dengan lampu tipe L 10080 buatan Indonesia dan masih banyak lagi yang lainnya. 
Berdasarkan hasil wawancara dengan pemilik perusahaan pembuatan stempel warna, laporanlaporan pengusaha jasa pembutan stempel warna yang ada dimasyarakat yang mayoritas adalah pengusaha jasa pembuatan stempel warna, beberapa permasalahan sering muncul terhadap mesin stempel flash itu.

Sebagai contoh adalah hasil wawancara dengan distributor mesin stempel flash buatan Indonesia merek MD (Bahan Stempel. Com) yang berlokasi di Tebet, Jakarta Selatan menyatakan bahwa sering mengalami masalah berupa mesin yang digunakan cepat panas pada box mesinnya. Berdasarkan hasil wawancara dengan pengusaha jasa pembuatan stempel warna yang menggunakan merek Flaz di daerah Bekasi menyatakan bahwa mesin buatan Cina yang dimilikinya memiliki hasil yang kurang merata didalam penyinaran karet stempelnya yang menjadikan kualitas cap tidak bagus karena berbayang/tidak fokus. Berdasarkan hasil wawancara dengan pengusaha jasa stempel warna didaerah Kramat Jati, Jakarta Timur yang menggunakan merek MD menyatakan bahwa mesin stempel buatan Indonesia yang dimilikinya cepat panas dalam operasinya ketika dioperasikan dengan intensitas yang tinggi. Sedangkan berdasarkan hasil wawancara dengan pemilik mesin stempel buatan Tiongkok merek flaz yang berada di Pontianak, Kalimantan Barat kecepatan operasi mesin menjadi kendala besar saat dituntut menyelesaikan pesanan dengan jumlah banyak.

Berbagai persoalan tentang kedua merek mesin stempel flash akan dijawab didalam penelitian ini, dengan harapan akan menemukan jawaban atas permasalahan tersebut. Dalam penelitian ini dari sekian banyak popolasi mesin stempel flash yang ada dimasyarakat maka diambil dua merek mesin stempel flash yang banyak beredar dimasyarakat yaitu mesin stempel flash merek MD buatan Indonesia dan mesin stempel flash merek Flaz buatan Tiongkok.

\section{METODE}

Pendekatan penelitian yang di gunakan adalah pedekatan kualitatif dengan metode penelitian grounded theory. Yaitu dengan cara melakukan penelitianterhadap objek, mengumpulkan data yang mendalam sehingga dapat ditemukan kesimpulan yang lebih mendalam. ( Sugiyono 2015:25). Alasan peneliti menggunakan pendekatan kualitatif grounded theory adalah beberapa permasalahan yang terjadi pada mesin stempel flash yang ada di lapangan adalah sebagai berikut :

a) Penyebab mesin stempel terjadi masalah baik performa ataupun hasil kerjanya belum diketahui secara pasti.

b) Perlu melakukan observasi, hal ini adalah pengukuran dan pengecekan terhadap mesin stempel tersebut baik dari kelistrikan maupun non kelistrikannya.

c) Untuk mengembangkan gagasan baru suatu bentuk rancangan mesin stempel yang ideal.

Untuk menguji kebenaran data yang ada mencakup spesifikasi komponen elektronik apakah dipergunakan sebagai mana mestinya sesuai dengan spesifikasinya.

\section{HASIL DAN PEMBAHASAN}

Indikator pengujian cap stempel meliputi poin-poin seperti warna hitam pekat pada karet stempel, permukaan yang mengkilap pada karet stempel, desain yang tercetak tajam pada karet stempel dan cap stempel yang tajam jika dicapkan pada kertas. Jika semua indikator tersebut terpenuhi maka stempel dinyatakan layak atau bagus dan kinerja mesin optimal.

Tabel 1. Indikator Kualitas Cap Stempel

\begin{tabular}{|c|c|c|}
\hline No. & $\begin{array}{c}\text { Indikator Penilaian } \\
\text { Stempel }\end{array}$ & Penjelasan \\
\hline 1. & $\begin{array}{l}\text { Warna hitam pekat } \\
\text { pada karet stempel } \\
\text { setelah disinari }\end{array}$ & $\begin{array}{l}\text { Warna hitam pekat } \\
\text { menunjukan tingkat } \\
\text { penyinaran sempurna } \\
\text { dan karet matang dan } \\
\text { akan tahan lama }\end{array}$ \\
\hline 2. & $\begin{array}{l}\text { Permukaan yang } \\
\text { mengkilap pada } \\
\text { karet stempel } \\
\text { setelah disinari }\end{array}$ & $\begin{array}{l}\text { Menunjukan pori-pori } \\
\text { yang sudah tertutup } \\
\text { rapat sehingga tinta } \\
\text { tidak akan menembus } \\
\text { bagian hitam }\end{array}$ \\
\hline 3. & $\begin{array}{l}\text { Desain yang } \\
\text { tercetak tajam } \\
\text { pada karet stempel } \\
\text { setelah disinari }\end{array}$ & $\begin{array}{l}\text { Logo/tulisan pada } \\
\text { karet terlihat timbul } \\
\text { daropada sisi karet yg } \\
\text { hitam }\end{array}$ \\
\hline 4. & $\begin{array}{l}\text { Cap yang tercetak } \\
\text { tajam pada kertas } \\
\text { setelah karet diisi } \\
\text { tinta }\end{array}$ & $\begin{array}{l}\text { Menunjukan cap } \\
\text { sempurna }\end{array}$ \\
\hline
\end{tabular}




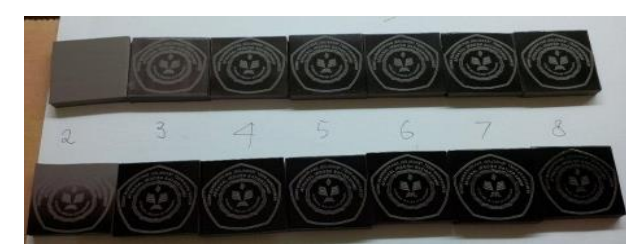

Gambar 1. Hasil Karet Yang Telah Disinari Oleh Kedua Mesin

a. Mesin Stempel Flash Made In Tiongkok Merek Flaz

Pengkuran besaran ini diukur dengan intrumen alat ukur yang sudah di tetapkan dengan menggunakan lama waktu operasi mesin dari 11 - t8. Sesuai dengan data hasil cap stempel yang menunjukan bahwa mesin stempel flash made in Tiongkok menunjukan waktu optimal pengisian pada 7 yaitu 7 detik pengisian energi. Pada waktu $\mathrm{t} 7$ daya yang digunakan mesin adalah sebesar 128,8 Watt. Daya senilai inilah yang ideal digunakan oleh mesin stempel flash made in Tiongkok untuk menjadikan cap stempel warna sempurna atau dengan kata lain memenuhi 4 kriteria stempel yang bagus.

Tabel 2. Pengukuran Lama Waktu Operasi Mesin Merek

\begin{tabular}{ccc}
\multicolumn{3}{c}{ Flaz } \\
\hline No. & Waktu (t1-t8) Detik & Daya Watt \\
\hline 1 & 1 & 55,80 \\
2 & 2 & 90,40 \\
3 & 3 & 114,80 \\
4 & 4 & 130,50 \\
5 & 5 & 136,20 \\
6 & 6 & 124,40 \\
7 & 7 & 128,50 \\
8 & 8 & 126,60 \\
\hline
\end{tabular}

Tabel 3. Pengukuran Besaran Mesin Stempel Flash Merek Flaz Dengan $t=7$ detik (waktu optimal)

\begin{tabular}{ccccccc}
\hline \multicolumn{1}{c}{ No. } & $\begin{array}{c}\text { Rangk } \\
\text { aian }\end{array}$ & Daya & $\begin{array}{c}\text { Ran } \\
\text { gkai } \\
\text { an }\end{array}$ & $\begin{array}{c}\text { W } \\
\text { ak } \\
\text { tu }\end{array}$ & Lux & Joule \\
\hline 1 & 440,0 & 132,3 & 0,32 & 7 & 34.000 & 985,60 \\
2 & 439,9 & 130,8 & 0,31 & 7 & 27.000 & 954,58 \\
3 & 437,8 & 136,6 & 0,27 & 7 & 24.100 & 827,44 \\
4 & 448,8 & 139,1 & 0,25 & 7 & 27.500 & 785,40 \\
5 & 440,0 & 139,3 & 0,26 & 7 & 32.400 & 800,80 \\
6 & 439,9 & 139,8 & 0,25 & 7 & 23.300 & 769,83 \\
7 & 439,9 & 132,7 & 0,27 & 7 & 30.900 & 831,41 \\
8 & 439,9 & 139,1 & 0,32 & 7 & 24.300 & 985,38 \\
9 & 439,9 & 137,8 & 0,32 & 7 & 31.300 & 985,38 \\
10 & 439,9 & 138,7 & 0,31 & 7 & 34.100 & 954,58 \\
Rata & 440,6 & 136,6 & 0,29 & 7 & 28.890 & 888,39 \\
-rata & 7 & 2 & & & & \\
\hline
\end{tabular}

Tabel 3 menjelaskan hasil pengujian sebanyak 10 kali dari kriteria mesin dalam kondisi optimal. Data yang didapat menunjukan bahwa rata-rata daya yang dibutuhkan sebesar 136,62 Watt dengan waktu konstan selama 7 detik maka sesuai dengan persamaan Energi adalah 888,39 Joule, energi rata-rata yang dibutuhkan mesin stempel flash made in Tiongkok merek Flaz untuk operasi optimal mesin.

b. Mesin Stempel Flash Made In Indonesia Merek MD

Dengan menggunakan lama waktu operasi mesin bervariasi dari $\mathrm{t}: 1-\mathrm{t}: 8$. Sesuai dengan data hasil cap stempel yang menunjukan bahwa mesin stempel flash made in Indonesia menunjukan waktu optimal pengisian pada $\mathrm{t} 3$ yaitu 3 detik pengisian energi. Pada waktu $t=3$ detik daya yang digunakan mesin adalah sebesar 471,3 Watt. Daya senilai inilah yang ideal digunakan oleh mesin stempel flash made in Indonesia untuk menjadikan cap stempel warna sempurna atau dengan kata lain memenuhu 4 kriteria stempel yang bagus.

Tabel 4. Pengukuran Lama Waktu Operasi Mesin

Stempel Flash Made In Indonesia Merek MD

\begin{tabular}{ccc}
\hline No. & Waktu (t1-t8) Detik & Daya Watt \\
\hline 1 & 1 & 371,40 \\
2 & 2 & 517,70 \\
3 & 3 & 473,10 \\
4 & 4 & 487,90 \\
5 & 5 & 465,90 \\
6 & 6 & 448,80 \\
7 & 7 & 419,00 \\
8 & 8 & 362,80 \\
\hline
\end{tabular}

Tabel 5. Hasil Pengukuran Besaran Mesin Stempel Flash Made In Indonesia Merek MD Dengan $\mathrm{t}=3$ detik (waktu optimal)

\begin{tabular}{ccccccc}
\hline No & $\begin{array}{c}\mathrm{V} \\
\text { Rangka } \\
\text { ian }\end{array}$ & $\begin{array}{c}\mathrm{P} \\
\text { Daya }\end{array}$ & $\begin{array}{c}\mathrm{I} \\
\text { Rang } \\
\text { kaian }\end{array}$ & $\begin{array}{c}\mathrm{t} \\
\text { Wa } \\
\text { ktu }\end{array}$ & $\begin{array}{c}\text { Lux } \\
\text { Lux }\end{array}$ & $\begin{array}{c}\text { Energi } \\
\text { Joule }\end{array}$ \\
\hline 1 & 348,00 & 446,90 & 1,67 & 3 & 34.300 & 1743,48 \\
2 & 350,00 & 414,80 & 1,60 & 3 & 29.000 & 1680,00 \\
3 & 352,00 & 390,30 & 1,66 & 3 & 24.600 & 1752,96 \\
4 & 347,00 & 410,00 & 1,63 & 3 & 35.000 & 1696,83 \\
5 & 352,00 & 374,00 & 1,68 & 3 & 34.600 & 1774,08 \\
6 & 348,00 & 340,00 & 1,56 & 3 & 32.300 & 1628,64 \\
7 & 349,00 & 374,00 & 1,65 & 3 & 29.800 & 1727,55 \\
8 & 350,00 & 413,80 & 1,59 & 3 & 22.600 & 1669,50 \\
9 & 350,00 & 367,00 & 1,71 & 3 & 35.000 & 1795,50 \\
10 & 349,00 & 392,60 & 1,55 & 3 & 22.400 & 1622,85 \\
\hline \multirow{2}{*}{ Ra } & 349,50 & 392,34 & 1,63 & 3 & 29.960 & 1709,06 \\
ta & & & & & \\
\hline
\end{tabular}


Tabel 5 menjelaskan hasil pengujian sebanyak 10 kali dari kriteria mesin dalam kondisi optimal. Data yang didapat menunjukan bahwa rata-rata daya yang dibutuhkan sebesar 392,34 Watt dengan waktu konstan selama 3 detik maka sesuai dengan persamaan Energi adalah 1709,06 Joule, energi rata-rata yang dibutuhkan mesin stempel flash made in Indonesia merek MD untuk operasi optimal mesin.

\section{$\underline{\text { Rangkaian Mesin Stempel Flash }}$}

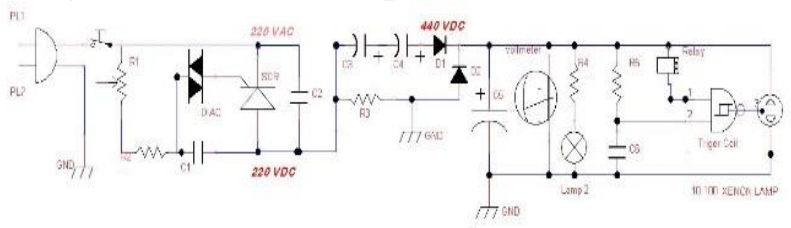

Gambar 2. Rangkaian Mesin Stempel Made In Tiongkok Merek Flaz

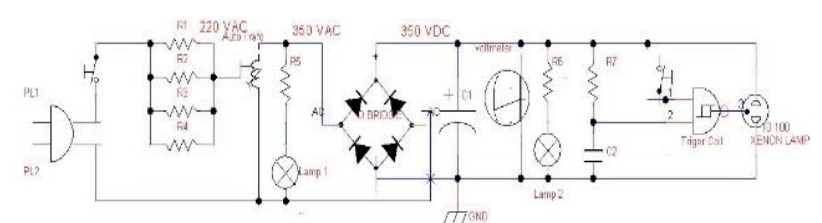

Gambar 3. Rangkaian Mesin Stempel Made In Indonesia Merek MD

Secara garis besar rangkaian ke dua mesin stempel flash ini hampir sama, hanya saja pada kedua mesin ini dibedakan pada rangkaian penyearah (rectifier) dari tegangan AC ke DC. Sistem penaikan tegangan dan besar tegangan yang dinaikan. Penjelasannya adalah sebagai berikut:

1) Pada mesin stempel made in Indonesia merek MD terlebih dahulu melewati resistor kapur sebagai tahanan dan kemudian tegangan dinaikan oleh Trafo Auto dari 220 VAC menjadi 350 VAC kemudian masuk ke rangkaian penyearah gelombang penuh (full wave rectifier) tipe bridge dengan 4 dioda. Pada saat level (+) dari keluaran trafo melewati forward bias pada D1 dan D4 maka akan diteruskan dan menjadi sisi positif (+), sebaliknya pada saat level (-) dari sumber maka akan dilewatkan pada dioda D2 dan D3 (reverse bias) dan selanjutnya menjadi sisi negatif (-). Selanjutnya tegangan yang dihasilkan disimpan didalam Capacitor Bank (C1). Tegangan yang dihasilkan dari penyearah ini sama dengan tegangan output trafo yaitu 350 VDC.

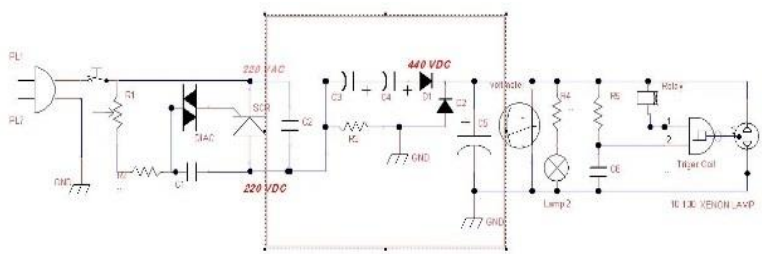

Gambar 4. Rangkaian Penaik Tegangan Mesin Stempel Made in Indonesia merek MD

2) Pada mesin stempel made in Tiongkok merek Flaz sebagai gerbang awal masuk ke rangkaian adalah Silicon Control Rectifier (SCR) sebagai pengendali tegangan tinggi sekaligus penyearah (Rectifier) setelah itu masuk ke rangkaian penyearah gelombang penuh dengan dua dioda, tegangan ini dinaikan dari 220 VDC menjadi 440 VDC melalui rangkaian seri kapasitor (C3 dan C4) dan selanjutnya muatan disimpan didalam Capacitor bank C5. Rangkaian penaik tegangan ini menggunakan prinsip batu baterai yaitu jika disusun secara seri maka tegangannya adalah jumlah masing-masing tegangan yang digabungkan $\left(\sum \mathrm{V}=\mathrm{V} 1+\mathrm{V} 2+\ldots \ldots . . . \mathrm{Vx}\right)$.

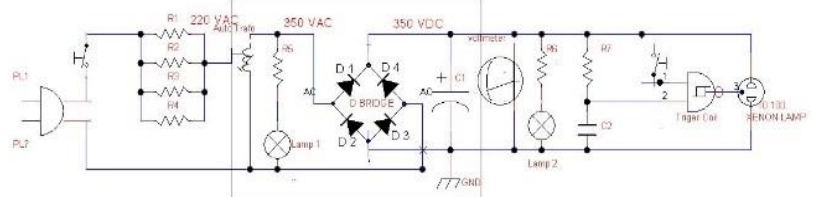

Gambar 5. Rangkaian Penaik Tegangan Mesin Stempel Merek Flaz

\section{b. Pembahasan Data}

1) Perbandingan Unjuk Kerja Berdasarkan

Kualitas Cap Stempel

Hasil cap stempel dikatakan baik berawal dari hasil penyinaran karet yang sempurna. Pada kedua mesin ini tampak perbedaan yang jelas dari hasil cap yang dihasilkan masing-masing mesin. Mesin stempel made in Tiongkok merek Flaz dapat beroperasi optimal pada $\mathrm{t} 7$ atau pada saat lama pengisian energi selama 7 detik, sedangkan mesin stempel made in Indonesia merek MD dapat beroperasi optimal $\mathrm{t} 3$ atau saat 3 detik pengisian energi. Dengan pengisian energi pada waktu optimalnya, maka hasil cap stempel pun mengikuti hasil penyinaran karet yang baik pula.

Dari data cap stempel yang dihasilkan maka data yang bisa diambil meliputi hasil cap stempel pada mesin stempel made in Tiongkok merek Flaz dikatakan sempurna pada lama pengisian energi selama 7 detik dengan daya 
sebesar 136,62 Watt dan energi sebesar 888,39 Joule. Sedangkan pada mesin stempel flash made in Indonesia merek MD cap stempel dikatakan sempurna pada lama pengisian energi selama 3 detik dengan daya sebesar 392,34 Watt dan energi sebesar 1709,06 Joule.

2) Perbandingan Unjuk Kerja Berdasarkan Pengukuran Besaran

Jumlah daya yang dibutuhkan mesin stempel flash made in Tiongkok merek Flaz rata-rata sebesar 136,6 Watt sedangkan Jumlah daya yang dibutuhkan mesin stempel flash made in Indonesia merek MD adalah rata-rata adalah 392,34. Maka perbandingan konsumsi dayanya adalah :

$$
\begin{aligned}
(\mathrm{P}) & =\mathrm{P}(\mathrm{MSFT}): \mathrm{P}(\mathrm{MSFI})=136,6: 392,34 \\
& =1: 2,87
\end{aligned}
$$

Dengan demikian maka perbandingan jumlah daya yang dibutuhkan dalam operasi mesin optimal rata-rata adalah $1: 2,87$ atau dapat dikatakan 2,87 kali lebih kecil daya yang digunakan mesin stempel made in Tiongkok.

Jumlah energi yang dikonsumsi mesin stempel flash made in Tiongkok merek Flaz adalah 888,39 Joule dan mesin stempel flash made in Indonesia merek MD 1709,06 Joule artinya jika dibandingkan maka energi yang dikonsumsi antara mesin stempel made in Tiongkok dengan mesin stempel flash made in Indonesia merek MD adalah :

$$
\begin{aligned}
(\mathrm{E}) & =\mathrm{E}(\mathrm{MSFT}): \mathrm{E}(\mathrm{MSFI})=888,39: 1709,06 \\
& =1: 1,92
\end{aligned}
$$

Dengan demikian dapat dinyatakan perbandingan energi yang dibutuhkan kedua mesin dalam kondisi optimal pengoperasiannya adalah $1: 1,92$.

Dilihat dari lama waktu pengoperasian mesin stempel flashnya pada mesin stempel flash made in Tiongkok merek Flaz memerlukan waktu 7 detik sedangkan mesin stempel flash made in Indonesia merek MD memerlukan waktu 3 detik dengan selisih waktu 4 detik.

$$
\begin{aligned}
(\mathrm{t}) & =\mathrm{t}(\text { MSFT }): \mathrm{t}(\text { MSFI })=7: 3 \\
& =2,3: 1
\end{aligned}
$$

Dari lama waktu operasinya maka perdandingan lama waktu operasi mesin stempel flash made in Tiongkok merek Flaz dengan mesin stempel flash made in Indonesia merek MD adalah 2,3 kali lebih cepat mesin stempel flash made in Indonesia merek MD.
Berdasarkan perhitungan unjuk kerja mesin stempel flash made in Tiongkok merek Flaz dan mesin stempel flash made in Indonesia maka dapat ditarik kesimpulan secara umum adalah untuk menghasilkan kualitas cap stempel ideal sesuai dengan idikator stempel yang bagus adalah pada tabel 6 dibawah ini.

Tabel 6. Perbandingan Indikator Mesin Stempel Flash

\begin{tabular}{ccccc}
\hline Indikator & Msft & Msfi & Perbandingan & Keterangan \\
\hline $\begin{array}{c}\text { Daya } \\
\text { (watt) }\end{array}$ & 136,62 & 392,34 & $01: 02,9$ & $\begin{array}{c}\text { MSFT 2,87 } \\
\text { kali lebih } \\
\text { rendah dari } \\
\text { MSFI } \\
\text { MSFT 1,92 } \\
\text { kali lebih } \\
\text { rendah dari } \\
\text { MSFI }\end{array}$ \\
$\begin{array}{c}\text { Energi } \\
\text { (Joule) }\end{array}$ & 888,39 & 1709,06 & $01: 01,9$ & $\begin{array}{c}\text { MSFI 2,3 kali } \\
\text { lebih cepat } \\
\text { dari MSFT }\end{array}$ \\
$\begin{array}{c}\text { Waktu } \\
\text { operasi } \\
\text { (detik) }\end{array}$ & 7 & 3 & $2,3: 1$ & \\
\hline Pada & tabel diatas & dapat diketahui & & \\
\hline
\end{tabular}

Pada tabel diatas dapat diketahui bahwa masing-masing mesin memiliki perbedaan nilai dari parameter daya, energi dan waktu operasi. Mesin stempel flash merek MD jauh lebih unggul dibandingkan mesin stempel flash merek Flaz dibuktikan dengan waktu operasi mesin yang lebih cepat 2,3 kali dibandingkan mesin merek Flaz. Mesin stempel merek MD hanya membutuhkan waktu 3 detik untuk mesin dapat beroperasi dengan optimal dengan jumlah energi yang disimpan yaitu 1709,06 Joule atau 1,92 kali lebih besar daripada mesin stempel flash merek Flaz yang hanya 888,39 Joule, itupun dengan waktu yang lebih lama yaitu 7 detik. Perbedaan lama waktu 4 detik dalam pengoperasian mesin menjadikan mesin stempel flash merek MD jauh lebih unggul dibandingkan mesin stempel flash merek Flaz. Jika waktu operasi selama 3 detik dijadikan parameter untuk kedua mesin ini maka pada saat itu mesin stempel flash merek Flaz belum mampu beroperasi atau dengan kata lain mesin stempel flash merek MD jauh lebih unggul dibandingkan mesin stempel flash merek Flaz. Kecepatan operasi mesin dan jumlah energi untuk menghasilkan kualitas cap stempel yang bagus ini menjadikan perbedaan yang signifikan kedua mesin stempel flash untuk ditentukannya keunggulan mesin tersebut

\section{KESIMPULAN DAN SARAN Kesimpulan}

a) Berdasarkan hasil cap yang dihasilkan maka unjuk kerja mesin stempel flash made in 
Indonesia merek MD lebih bagus dibandingkan mesin stempel flash made in Tiongkok merek Flaz.

b) Berdasarkan lama waktu operasi, unjuk kerja mesin stempel flash made in Indonesia merek MD lebih cepat 4 detik dibandingkan mesin stempel flash made in Tiongkok merek Flaz.

c) Berdasarkan pemakaian daya dan konsumsi energi listrik, unjuk kerja mesin stempel flash made in Tiongkok merek Flaz lebih efisien dibandingkan mesin stempel flash made in Indonesia merek MD.

Maka dapat disimpulkan menurut parameter unjuk kerja mesin stempel flash yang baik dan memenuhi standar didalam proses produksi ada dua indikator yaitu pertama adalah kualitas cap stempel yang dihasilkannya, kedua adalah kecepatan didalam operasi mesinnya. Sesuai dengan parameter tersebut maka kesimpulannya adalah unjuk kerja mesin stempel flash made in Indonesia merek MD lebih bagus dibandingkan mesin stempel flash made in Tiongkok merek Flaz.

\section{Saran}

Berdasarkan hasil penelitian ini maka disarankan untuk mengembangkan mesin stempel ideal dengan memaksimalkan nilai tegangan rangkaian dengan dengan memaksimalkan besar tegangan yang dinaikan pada mesin stempel flash merek MD sehingga energi yang dihasilkan maksimal. Karena menurut persamaan energi bahwa besar energi berbanding lurus dengan besar tegangan, dan lama waktu operasi mesin.

Pada mesin stempel flash merek Flaz supaya menghasilkan jumlah energi yang maksimal maka nilai rangkaian perlu diperbesar.

Tambahkan rangkaian pendingin berupa kipas pendingin atau pendingin logam pada komponen yang mudah panas agar kinerjanya tidak terganggu.

\section{DAFTAR PUSTAKA}

Asauri, Sofjan. 2004. Manajemen Produksi dan Operasi. Jakarta: LP FEUI.

Bishop, owen. 2000. Dasar-dasar Elektronika. Jakarta: Erlangga.

Fakultas Teknik. 2016. Buku Panduan Penyusunan Skripsi dan Non Skripsi. Jakarta: Fakultas Teknik, Universitas Negeri Jakarta.
Hasan, A. 1949. Cap, Stempel dan Materai. Jakarta: Balai Pustaka.

Sapiie, Soedjana \& Nishini, Osamu. 2000. Pengukuran Dan Alat-Alat Ukur Listrik, Edisi ke-6. Jakarta: PT. Pradnya Paramita.

Siregar, W. 2004. Electrical Utilities. Jakarta: Erlangga.

Sugiyono. 1999. Metode Penelitian Bisnis. Bandung: Alfa Beta.

Sugiyono. 2015. Metodologi Peneliian R\&D. Bandung: Alfa Beta.

NN. 2015. Data Sheet Flash Lamp. http://exelitas.com/datasheet-lampflash.html. (akses 30 Desember 2016)

NN. 2016. Perbedaan Antara Stempel Warna Dengan Runaflek Dan Trodat. http://vijasmart.com/perbedaan-antarastempel-warna-dengan-runaflek-dan-trodat (akses 30 Desmber 2016)

NN. 2016. Konsep Photograpi. http://rrphotograph.weebly.com/blog/ sejarah-dan-pengertian-flash (akses 1 januari 2017)

NN. 2016. Data Sheet Flash Lamp. http://exelitas.com/datasheet-lampflash.html. (akses 30 Desember 2016)

NN. 2016. Trigger Coil. http://www.xenonflashtubes.com/triggercoil-transformer.html. (Akses 24 Desember 2016)

NN. 2016. Photosesnsitive Seal Machine. http://www.printermanufacture.com/Photosensitive-SealMachine-Rubber-Stamp-Machine-p985.html (Akses 24 Desember 2016) 